\title{
Spina Bifidalı Hastada Ağır Nöropatik Ülser ve Fungal Dermatit
}

\section{Severe Neuropathic Ulcer and Fungal Dermatitis in a Patient with Spina Bifida}

\author{
Çisem Aksu, Neslihan Çiçek Deniz* , Nurdan Yıldız* Ayşe Deniz Yücelten** , Harika Alpay* \\ Marmara Üniversitesi Tıp Fakültesi, Çocuk Sağlığı ve Hastalıkları Anabilim Dalı, istanbul, Türkiye \\ *Marmara Üniversitesi Tıp Fakültesi, Çocuk Nefrolojisi Bilim Dalı , Istanbul, Türkiye \\ **Marmara Üniversitesi Tıp Fakültesi, Deri ve Zührevi Hastalıkları Anabilim Dalı, İstanbul, Türkiye
}

Özet

Kaudal nöral açıklığın yanlış kapanması spina bifida (SB) olarak bilinen vertebral ark defektlerini oluşturur. Sıklığı 4-5/10.000 canlı doğumdur. Medulla spinalisin kese şeklinde dışarı çıktığı spina bifida sistika nöral tüp defektinin düzeyi ile uyum gösteren ağır nörolojik kusurlara yol açar. Duyu kaybı, paralizi, barsak ve mesane fonksiyon kaybı sıktır. Hastaların paraliziye bağlı postürlerinden kaynaklanan bası ülserleri ve cilt lezyonları sık rastlanan tıbbi problemlere odaklanılığında gözden kaçabilir ve önemli sorunlara yol açabilir. Bu yazıda idrar yolu enfeksiyonu ve hipertansiyon nedeni ile başvuran, fizik muayenesinde gluteal bölgelerde yaygın dermatiti ve sağ dizinde derin bası ülseri saptanan SB'li on bir yaşında bir erkek olgu sunulmuş, hastaların uzun dönem izlemlerinde ortaya çıkabilen ve yaşam kalitesini düşüren lokal komplikasyonlara dikkat çekilmek istenmiştir. (Haseki Tıp Bülteni 2013; 51: 186-9)

Anahtar Kelimeler: Spina bifida, bası ülseri, dermatit
Abstract

Spina bifida (SB) is a congenital abnormality characterized by incomplete closure of the neural tube early in gestation. The incidence of SB is 4-5 per 10000 live births. In SB sistica, the spinal cord protrudes through the spinal column, resulting in nerve damage depending on the location and the size of the spinal lesion, and physical disabilities including lower limb paralysis and disrupted bladder or bowel function. Pressure ulcers due to the position of the patient and the skin lesions may develop and be underdiagnosed while the most common and severe medical problems are focused on. In this case report, we present an eleven-year-old SB patient who was admitted with urinary tract infection and hypertension and had bilateral gluteal dermatitis and severe pressure ulcer on his right knee. We aimed to draw attention to local complications which may appear during followup throughout life and decrease the quality of life. (The Medical Bulletin of Haseki 2013; 51: 186-9)

Key Words: Spina bifida, pressure ulcer, dermatitis

\section{Giriş}

Nöral tüpün dördüncü gestasyon haftası sonunda defektif kapanması vertebralarda ya da spinal kordda anomalilere neden olur. Bu anomaliler izole vertebral ark defektlerinden spinal kordun malformasyonlarına kadar değişir (1-3). En ciddi defektlerden biri olan lumbosakral meningomyelosel alt ekstremitelerde his kaybı veya paralizi, mesane ve bağırsak disfonksiyonuna yol açar. Bu hastalar inkontinans nedeni ile alt bezi kullanmak zorunda kalırlar. Idrarla sürekli temas sonucu bez bölgesinde dermatit kolaylıkla gelişebilir. Nörolojik hasara bağlı his kaybı ise bası ülserlerinin gelişimine yol açar (2-5).

Hastalar nefrolojik, ortopedik ve cerrahi sorunları nedeniyle farklı branşlar tarafından izlenirler. Ancak bu ana problemlerin yanında cilt lezyonları ve bası ülserleri gibi lokal komplikasyonlar sıklıkla gelişebilir. Postür değişikliği ve uygun bakım ile önlenebilecek olan, özellikle kapalı bölgelerdeki cilt lezyonları ayrıntılı fizik muayene yapılmadığında gözden kaçabilmektedir. Ağır lezyonlar
Yazışma Adresi/Address for Correspondence: Harika Alpay

Marmara Üniversitesi Tıp Fakültesi Pendik Eğitim ve Araştırma Hastanesi

Mimar Sinan Caddesi Fevzi Çakmak Mah.No:41 Üst Kaynarca- Pendik / İstanbul, Türkiye GSM: +90 5326451515 E-posta: harika.alpay@gmail.com

Geliş Tarihi/Received: 11 Şubat 2013 Kabul Tarihi/Accepted: 16 Nisan 2013
Haseki Tıp Bülteni,

Galenos Yayınevi tarafından basılmıştır.

The Medical Bulletin of Haseki Training and Research Hospital, published by Galenos Publishing. 
hasta ve ailesinin yaşam kalitesini düşürür, ayrıca enfeksiyon odağı haline gelebilir.

Bu yazıda on bir yaşında bir erkek olgu sunularak SB'lı hastaların uzun dönem izleminde özellikle kapalı bölgelerde ciddi deri lezyonlarının gelişebileceğini ve bu lezyonların ayrıntılı fizik muayene ve anamnez ile en aza indirilebileceğini vurgulamak amaçlanmıştır.

\section{Olgu}

Yirmi yedi yaşındaki anneden miyadında, normal spontan doğum ile doğan hastanın postnatal birinci gününde lumbosakral meningomyelosel nedeni ile opere edildiği öğrenildi. On beş günlükken ventriküloperitoneal (VP) şant takılan hasta nörojenik mesane nedeni ile çocuk nefrolojisi polikliniğinde izleme alındı. Sekiz yıldır kontrollerine gelmeyen hasta evde baş dönmesi ve konvulsiyon geçirmesi üzerine acil polikliniğimize başvurdu. Labaratuvar incelemelerinde kan şekeri: 88 $\mathrm{mg} / \mathrm{dl}, \mathrm{Na}: 139 \mathrm{mEq} / \mathrm{L}, \mathrm{K}: 4.2 \mathrm{mEq} / \mathrm{L}$, Ca: $10 \mathrm{mg} / \mathrm{dL}$, Mg: $2.4 \mathrm{mg} / \mathrm{dL}, \mathrm{P}: 5.6 \mathrm{mg} / \mathrm{dL}, \mathrm{PTH}: 188 \mathrm{pg} / \mathrm{mL}$, serum BUN: $40 \mathrm{mg} / \mathrm{dl}$, kreatinin: $3 \mathrm{mg} / \mathrm{dl}$, glomeruler filtrasyon hızl: $20 \mathrm{ml} / \mathrm{dk} / 1.73 \mathrm{~m}^{2}$ idi. Kan gazında $\mathrm{pH}: 7.42, \mathrm{PCO}_{2}$ : 33.5 HCO3:21.5 BE: -2.3 Lac: $1 \mathrm{mmol} / \mathrm{L}$ olarak görüldü. Fizik muayenesinde kan basıncı 153/75 mm Hg saptandı. Konvulsiyonu hipertansiyona bağlandı, antihipertansif tedavisi Amlodipin $10 \mathrm{mg} / \mathrm{gün}$ ve Enalapril 20 mg/gün olarak düzenlendi. İki ay sonra baş ve bel ağrısı şikayetleri ile tekrar başvuran hasta VP şant disfonksiyonu düşünülerek servisimize yatııldı. Fizik muayenesinde sağ gluteal ve inguinal bölgede daha yaygın olan bilateral, hiperemik zemin üzerinde pullanma gösteren ve çevrelerinde satellit püstüller olan deri lezyonları tespit edildi (Resim 1). Alt ekstremitelerinde total paralizi ve açıklığı sağa bakan skolyozu mevcuttu. İdrar ve gaita inkontinansı nedeniyle

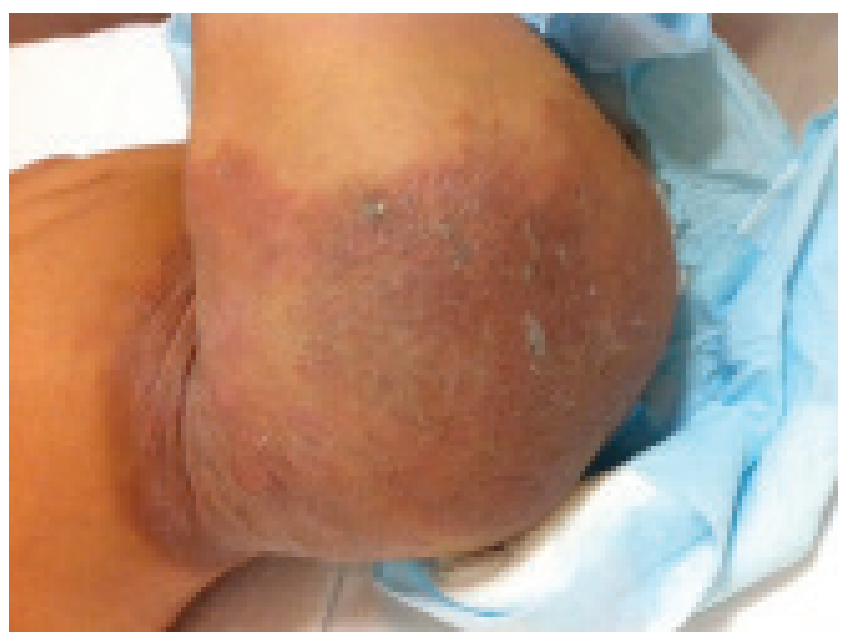

Resim 1. Sağ gluteal bölgede çevresinde satellit papül ve püstüller görülen dermatit bezlenmekte ve nörojenik mesane nedeni ile günde altı kez temiz aralıklı kataterizasyon uygulanmaktaydı. İskelet deformitesi nedeniyle diz üstü oturan hastanın sağ dizinde $3 \times 3 \mathrm{~cm}$ çapında yaygın inflamasyon bulguları gösteren bası ülseri saptandı (Resim 2, 3). Gluteal lezyonlarından alınan kazıntı örneği potasyum hidroksit ile incelendiğinde hif veya spor tespit edilemedi ancak hiperemik zemin

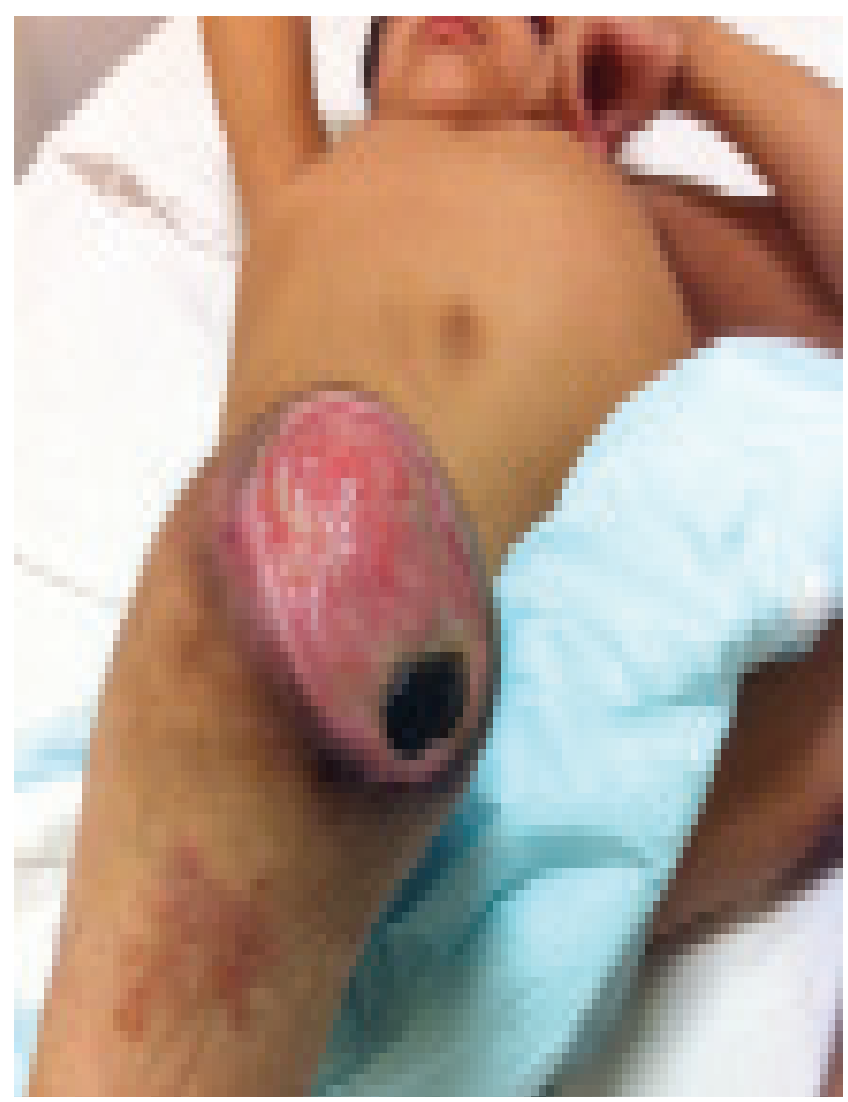

Resim 2. Sağ dizde ağır bası ülseri

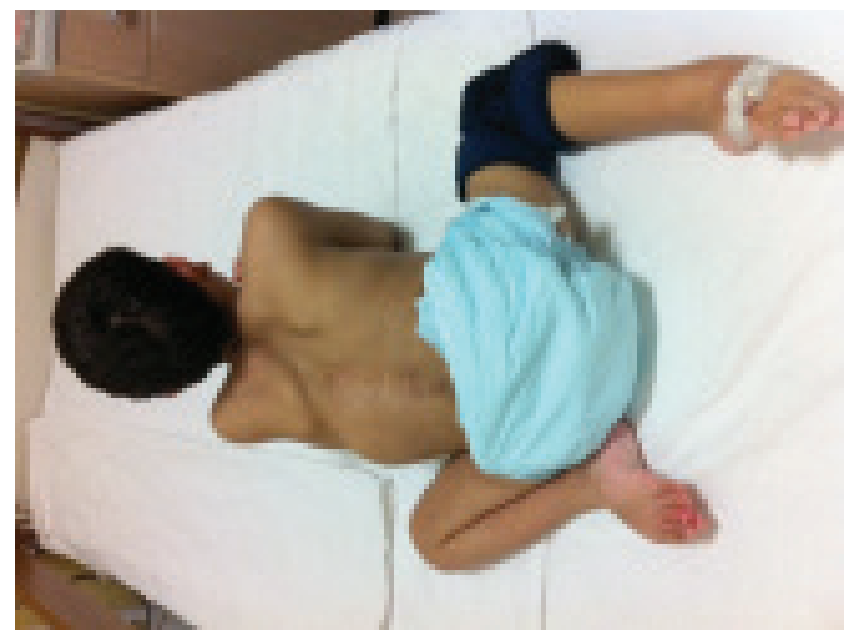

Resim 3. Diz üstü oturuş poziyonu 
üzerindeki pullanmalar ve çevresindeki satellit püstüller klinik görünüm olarak kandida ile uyumlu bulundu. Topikal antifungal tedavi başlandı, dizdeki bası ülseri için gümüş nitratlı yara pansumanı önerildi. Ayaktan izleminde bez bölgesindeki dermatiti üç ay içerisinde geriledi, dizdeki bası ülseri için bir yanık merkezinden takibine devam edildi.

\section{Tartışma}

Spina bifida uzun dönem izlem ve tedavi için multidisipliner yaklaşım gerektiren bir hastalıktır. Profesyonel sağ lık hizmeti kadar aile bakımının da gerektiği bu süreçte birincil tıbbi sorunlara odaklanıp olası lokal komplikasyonları gözden kaçırmak yaşam kalitesini uzun vadede azaltacaktır (3). Uzayan yaşam süresi ile birlikte bakım konusunda hastanın sorumluluğu ve bilinç düzeyi artmaktadır ancak komplikasyonlar aynı oranda azalma göstermemektedir (6).

Daha iyi medikal ve cerrahi tedavi ile yenidoğan dönemindeki sağ kalım oranı \%92'lere kadar çıkmıştır (4, 5). Ancak dikkat edilmesi gereken konulardan biri lezyon seviyesine göre klinik şiddeti değişen paralizi, mesane ve bağırsak disfonksiyonu yanında hareketsiz yaşam tarzı ve his kaybına bağlı gelişen nöropatik ülserlerdir. Çoğunlukla basınca maruz kalan sırt, gluteal bölge ve diz kapakları üzerinde gelişen nöropatik ülserler bası ve kronik irritasyon sonucu oluşmaktadır (7). Hastamız anatomik yapısındaki bozukluk ve alt ekstremitelerdeki paralizi nedeniyle dizlerinin üzerinde oturmaktaydı. Sürekli basıya bağlı sağ dizinde derin ülseri mevcuttu. Bası ülserlerinin tedavisi uzun sürebilmekte ve hastanın yaşam kalitesinin düşürmektedir. Bu lezyonların uygun poziyon verilerek gelişiminin önlenmesi büyük önem taşır. Michael ve ark'ın yaptığı çalışmada tekerlekli sandalye kullanan spina bifida ve spinal kord travmalı hastaların arkaya doğru 20 derece eğim ile oturmalarının pelviste basıya bağlı ülserleri önemli ölçüde azalttığı gösterilmiştir (5). Uygun oturuş pozisyonunda ağırlık her iki iskial tümsek arasında eşit paylaştııımalıdır. Ancak meningomyelosel tanılı birçok hastada oturma dengesi bozulmuştur. Ek olarak skolyoz gelişimi pelvisin oblik eksene kaymasına ve eşit olmayan basınç dağıımı nedeni ile cilt bütünlüğünün bozulmasına yol açmaktadır. Drummond ve ark. bası ülseri gelişiminde dört risk faktörü belirlemişlerdir. Bunlar hastanın hareketsiz olması, vücut ağılığının \%30'dan fazlasının tek iskium, $\% 11$ 'den fazlasının sakrum/koksiks, $\% 55$ 'den fazlasının sırt üstünde olmasıdır (8). İskelet deformiteleri hastanın ve ailenin tedaviye uyumunu etkilemekte, bu durum hastanın nörolojik, nöroşirürjik, ortopedik ve nefrolojik sorunlarının tedavisinde aksamalara yol açabilmektedir. Benzer ve ark. alt ekstremitelerini hareket ettiremeyen meningomyeloselli hastalarda yürüyebilme yeteneği olan hastalara göre daha fazla renal skar saptamışlardır (6). Bizim hastamızın ağır skolyozu ve postür bozukluğu mevcuttu, normal oturma pozisyonu yoktu. Ailenin tedaviye uyumsuzluğu nedeniyle takipsiz geçen zaman içinde renal hasar ve kronik böbrek yetersizliği gelişmiş̧i.

Spina bifidalı hastaların idrar ve gaita inkontinansı nedeniyle çoğunlukla bezlenmesi idrar ve dışkı temasına bağlı cilt lezyonlarının gelişimini, özellikle de bez dermatiti ve kandida enfeksiyonunu kolaylaştııı. Reepitelizasyonun bozulduğu kronik irritasyon durumlarında cildin dermis tabakasına ilerleyen epitel dokusu yabancı cisim reaksiyonuna yol açar ve rejenerasyonu bozar. Bu süreç malign transformasyona kadar ilerleyebilir. Ayrıntılı fizik muayene ile tespit edilebilecek olan ülser bölgesinde kitle oluşumu, yeni başlayan ağrı, varsa drenajın kokusu, miktarı veya görünümündeki değişiklikler malign değişim yönünde uyarıc olabilir. Lokal yara yeri bakımı ve sık pozisyon değiştirme bu inflamatuar süreci durdurur (7). Hastaların poliklinik şartlarında her muayenelerinde bez bölgesinin açılarak ayrıntılı muayene edilmemesi durumunda bu lezyonlar kolaylıkla gözden kaçabilir. Hastamız kontrolsüz geçen sekiz yıllık bir süreçten sonra acil polikliniğimize hipertansif ensefalopati bulgularıyla başvurmuştu. Acil poliklinik şartlarında konvulsiyon ve hipertansiyona yönelik tedavileri yapılırken bez bölgesindeki lezyonu acil sorun olarak değerlendirilmemişti.

Bez dermatiti gluteal ve genital bölge, alt batın ve üst uylukta oluşur. Bu bölgelerde lezyonların görülmesi durumunda ayırıcı tanıda kandidiyazis, irritan kontakt dermatit ve atopik egzema akılda tutulup uygun tedavi seçilmelidir (7-11).

Hastamızın lezyonlarının kandida ile uyumlu bulunması nedeni ile topikal antifungal tedavisi başlandı, dizdeki ülseri için gümüş nitratlı pansuman bantı önerildi. Hastanın poliklinik takiplerinde bez bölgesindeki dermatitinin idrar ve gaita teması nedeniyle oldukça yavaş gerilediği görüldü.

Sonuç olarak spina bifida tanılı hastaların izleminde çocuk nefrolojisi ve ürolojisi, beyin ve sinir cerrahisi, ortopedi bölümleri gibi multidisipliner bir yaklaşımın gerekliliği kaçınımazdır. Hastaların sık rastlanılan sorunlarına yönelik medikal ve cerrahi tedaviler etkin bir şekilde uygulanır. Ancak ayrıntıı bir fizik muayene ile ortaya çıkabilecek diğer lokal komplikasyonların hastanın gündelik yaşantısında en az birincil medikal sorunlar kadar önemli bir yer tutabileceği unutulmamalıdır. Bu nedenle hastaların bez bölgesi gibi kapalı alanları lokal lezyonlar açısından ayrıntılı olarak değerlendirilmelidir. 


\section{Kaynaklar}

1. Shin M, Besser LM, Siffel C, et al. Prevelance of Spina Bifida Among Children and Adolescents in 10 Regions in the United States. Pediatrics 2010;126:274-9.

2. De Jong TP, Chrzan R, Klijn AJ, Dik P. Treatment of the neurogenic bladder in spina bifida. Pediatr Nephrol 2008;23:889-96.

3. Stepansky MA, Roache CR, Holmbeck GN, Schultz K. Medical Adherence in Young Adolescents with Spina Bifida: Longitudinal Associations with Family Functioning. J Pediatr Psychol 2010;35:167-76.

4. Fletcher JM, Brei TJ. Introduction: Spina Bifida: A multidisciplinary Perspective. Dev Disabil Res Rev 2010;16:15.

5. Short K, Frimberger F. A review of the Potential for Cardiometabolic Dysfunction in Youth with Spina Bifida and the Role for Physical Activity and Structured Exercise. Int J Pediatr. doi: 10.1155.2012/541363.
6. Benzer M, Alpay $H$, Altuntaş Ü, ve ark. Meningomiyeloselli Hastaların Yürüyebilme Durumunun Böbrek Hastalığı ile iliş̧kili Klinik ve Radyolojik Bulgulara Etkisi Var mı? Turk Neph Dial Transpl 2012;21:258-61.

7. Nthumba PM. Marjolin's ulcers: theories, prognostic factors and their peculiarities in spina bifida patients. World J Surg Oncol 2010;8:108-12.

8. Patel J, Walker JL, Talwalkar VR, et al. Correlation of Spine Deformity, Lung Function and Seat Pressure in Spina Bifida. Clin Orthop Relat Res 2011;469:1302-7.

9. Kellen PE. Diaper Dermatitis: Differential Diagnosis and Management. Can Fam Physician 1990;36:1569-72.

10. Al-Faraidy NA, Al-Natour SH. A forgotten complication of diaper dermatitis: Granuloma gluteale infantum. J Family Community Med 2010;17:107-9.

11. McLimont CS, Qwen LJ, Wright GJ. Can children with spina bifida and muscular dystrophy participate in their own health status evaluations? J Child Orthop 2010;4:253-8. 